\title{
Elogio del diletante, \\ - la alegría de las cosas finitas
}

Luciano Espinosa

Universidad de Salamanca

espinosa@usal.es

\section{A Praise of the Dilettante, or the Joy in Finite Things}

\begin{abstract}
Resumen: Esta clase de diletante -que vive en medio de una crisis de civilización- es capaz de ejercer el discernimiento personal, sin miedo ni frivolidad, de acuerdo a sus propias circunstancias y preferencias. No es una actitud caprichosa, sino cultivada y alegre, que presta atención a la belleza de las cosas finitas. El perfil del amateur es tanto ético como estético y se dibuja en diálogo con Weber, Lichtenberg y Bordieu. Por otro lado, hablamos de un mediador -no un especialista- que construye relaciones entre una teoría objetiva (Steiner) y otra subjetiva (Wilde) del arte, de cara a crear un modo de vida enriquecido y autónomo, tal como hizo Montaigne.
\end{abstract}

Palabras-clave: diletante, conocimiento, arte, alegría, crisis, autonomía
Abstract: This kind of dilettante -who lives in the middle of a crisis of civilization- is able to exercise a personal discernment, without fear or frivolity, according to the own circumstances and preferences. It is not a capricious attitude, but a cultivated and joyful one, paying attention to the beauty in finite things. The amateur outline is both ethical and esthetical and it is drawn in a dialogue with Weber, Lichtenberg and Bordieu. On the other hand, we are talking about a mediator - not a specialist- that builds relations between an objective (Steiner) and a subjective (Wilde) theory of art, in order to create an enriching and autonomous way of living, like Montaigne did.

Keywords: dilettante, knowledge, art, joy, crisis, autonomy

\section{Una disposición general ante la vida}

1.1. Conviene salir pronto al paso de la mala fama que tiene el diletantismo, entendido como puro divertimento e incluso frivolidad, para hacer valer su etimología ligada a la delectación, como es sabido: el diletante es también quien disfruta con criterio y discernimiento (delectus) de cuanto le rodea, precisamente porque su rasgo principal es el de aficionado o amateur, es decir, quien ama sin imponer la voluntad de poder ni la utilidad a lo que hace. Y para ello cultiva el buen gusto (en la amplia acepción del término) como la mejor vía de cualificar su experiencia, que por lo demás no tiene empacho en reconocer que siempre es contingente, esto es, unida al contacto (tangere). Digamos que acoge toda clase de vivencias estéticas sin prejuicios en lo que cabe, aceptando las diversas caras de la fortuna pero buscando siempre el gozo posible. Bajo este punto de vista, no trata de acumular sensaciones sino aprovechar el carácter nómada de la existencia y convertirlo en una forma de hedonismo inteligente (valga la redundancia), lo que a su vez implica tener conciencia de los límites y de los contextos. 
El diletante apuesta por su propio criterio frente a la tiranía del mercado socioeconómico, profesional o de estatus, pero también contra el imperio de la seriedad y el supuesto rigor que muchas veces diseccionan y matan al objeto de su afán. Sabe que necesita educarse para lograr mayor placer en su actividad, la que fuere, y por eso descarta el mero capricho, aunque sin aceptar la solemnidad de quien dice prescindir de los propios condicionantes biográficos, históricos o afectivos. Ejerce la tolerancia genuina y el eclecticismo, receptivo a la pluralidad y al cambio interno o externo, abierto a la verdad que pueda hallar en el camino, pues tan sólo la trata desde una posición más modesta a la par que orgullosa. No es un dandi que exagere las poses, sino alguien que ensaya sin descanso, es decir, que decanta y aquilata las cosas mediante el alambique de un juicio siempre en marcha; como tampoco es un cínico que esté de vuelta en la búsqueda ética de la lucidez.

De hecho, este tipo de diletantismo toma como punto de partida la finitud, siempre vulnerable al dolor, pero no condesciende a quedarse ahí anclado y mucho menos a quejarse. Tiene demasiadas cosas que aprender y gozar como para abandonarse al lamento o ceñirse a una sola faceta de lo real. De ahí que sea muy capaz de entender a Hegel cuando habla de "la tristeza de las cosas finitas" (die Trauer der Endlichkeit) ${ }^{1}$ en la Ciencia de la Lógica (1, 2, B, c), pero está más dispuesto a reivindicar la alegría que también les es inherente como el reverso que estalla gratuito, sin por qué ni para qué. Luego no tiene problema en asumir lo perecedero, sin aspirar a ningún suplemento (ontológico, moral o finalista) de sentido global, en el bien entendido hegeliano de que esa invocación de la infinitud sólo cabe plantearla desde el aquí y el ahora. Como el propio Hegel dice, todo lo existente tiene un fundamento y es condicionado desde la perspectiva solidaria del conjunto, pero es a la vez incondicionado y carece de fundamento dado que el universo sólo existe en sus momentos finitos (Hegel, 1968: I, 124). El diletante opta por esta segunda línea, sin buscar la seguridad de los lazos con el Todo frente a la caducidad del no-ser implícito en la finitud. Luego tampoco le obsesiona la perfección y además desdramatiza la "muerte del arte" que el alemán vaticinó ante la ruptura de los cánones.

El punto de partida es convertir sus humores en tanteos y filtros porque recela del principio de autoridad y de cualquier dogma, dispuesto como está a arriesgar en sus elecciones. Si esto significa anteponer la ilusión e incluso lo imaginario (entendido como suma de sensación, percepción e invención), no hay inconveniente en quedarse con los reveladores accidentes en vez de con las esencias inalcanzables de las cosas. 
Claro que ya Aristóteles (Met., $8,7,12$ ) y después Tomás de Aquino (De veritate IV $, 1,8$; De spiritualibus creaturis 2,3) dejan ver que las formas sustanciales son desconocidas y sólo accesibles a través de sus propiedades y efectos. Acaso esta vía humilde de contacto es la que más ofrece porque hace presentes (prae-sensu, prae-ens, prae-essentia) las cosas cuando se afinca en una experiencia con menos mediaciones, que no bruta o inmediata. Por otro lado, como enseñó Heráclito y acuña Platón, "todo fluye" (Cratilo, 402a), luego nada más apropiado que estar atento y fluir también dejándose ir (que no llevar), de forma que el sabio sea el que obedece a su propio daimon, que es el que realmente sabe (Cratilo, 396b). El subjetivismo del diletante no se conforma con menos y lleva esa coherencia hasta el final, aunque viva sin la red del prestigio y no tenga certezas definitivas. Por eso alardea del cultivo del ocio como una actitud vital (frente al negocio) que le permite cultivarlo en la escuela (schole) siempre renovada que es el mundo.

1.2 No discutiremos sobre la naturaleza del arte (valga la paradoja), que -como dijo J. A. Whistler- es algo que simplemente ocurre (Art happens), sino que nos ocupará una buena actitud para acercarse a él. Por ejemplo, la que reconoce que la maestría en cualquier asunto exige gran preparación y perseverancia, pero advierte que esa disciplina previa queda después incorporada y enmudece para aflorar sin esfuerzo al servicio de la inspiración del momento. El conocimiento y la habilidad técnica son condiciones necesarias pero no suficientes y el milagro artístico en particular tiene un plus de sentido gratuito e inexplicable. Visto desde una óptica amplia -en palabras de J. Wagensberg-, la ciencia comprende sin necesidad de intuir y es teoría para la experiencia, mientras que el arte intuye sin necesidad de comprender y es experiencia para la teoría ("El arte en aforismos", EL País BABELIA, 8-3-2014). Cada actividad nos fascina por separado (aunque siempre haya cruces) y proporciona lo que las otras no pretenden dar. Mi propuesta es que el diletante -que no es maestro en nada- puede tener la capacidad de abrirse a esas miradas diferentes e integrar en sí mismo sus frutos complementarios. Acaso ahí estriba el valor de la no especialización que los griegos llamaban polimatía y que demandaba también el arte de la proporción y la medida a la hora de combinar los diversos saberes. Algo por cierto en lo que los sofistas cumplieron un papel más destacado de lo que se les reconoce como valedores del artificio civilizador, en beneficio de la difusión de la cultura y de la democracia (Espinosa, 1995). 
Con la ventaja añadida de que este tipo de aprendiz versátil incurre menos en el ridículo y la pedantería que tanto ha molestado siempre: Luciano de Samósata (y después Rabelais) llama morosofoi al sabihondo que desbarra (sufre logorrea) y no para de discutir neciamente sobre cualquier cosa del vasto universo, mientras embiste a los rivales sin saber reír (Luciano, 1987: 86); y Erasmo de Rotterdam reivindica la sana locura (hermana de la filautía) frente a la gravedad de esos filósofos torpes para la vida cotidiana que, además de no saber bailar y aguar todas las fiestas, "quieren elevarse al estado de los dioses" y prescindir de las pasiones que los humanizan (Erasmo, 1984: 69s, 76, 98s., y 86). Se trataría, por contra, de abrirse a una realidad plural y hacer patentes los aprendizajes en el propio sujeto antes que nada, con cierta soltura y destreza en la praxis. Aspirar a eso que llaman el "arte de vivir", aunque a menudo sea un mero bricolage de aficionados que se aplican, eso sí, con empeño y dedicación. Supongo que el diletante sabrá reírse entonces de sí mismo y de cuantos aparezcan engolados a su vera, pues no hay mejor lucidez que el humor...

\section{Una breve genealogía y el sentido de la oportunidad}

Conviene recordar algunos elementos que permiten entender por qué la figura del diletante es oportuna en este momento histórico. Es sabido que en el último cuarto del siglo XIX y el primero del XX se produjo una auténtica revolución sociocultural que afectó a todos los órdenes de la vida burguesa, dando paso entre las élites a un rechazo progresivo de los formalismos morales, a la burocratización, el mercantilismo, los tipos de lenguajes y significados establecidos, la mecanización, etc., a la par que una innovación simbólica de todo tipo abría la puerta al desarraigo, la anomia, el irracionalismo, la creatividad... Cosas todas que en el arte encontraron una expresión privilegiada, rica y punzante, independizándolo de las ataduras convencionales del realismo y más espiritual de lo que pensaban los escandalizados críticos o los pesimistas padres de la sociología (Stromberg, 1990: 320, 326s.). Para las distintas vanguardias ya no sirven los referentes objetivos de la naturaleza y tampoco el genio subjetivo que el romanticismo había exaltado, sino una búsqueda libérrima y exasperada de formas valiosas por sí mismas, casi autónomas, llenas de fuerza, de absurdo, trivialidad, desolación o humor (Trías, 1988: 240, 255ss.). Y lo mínimo que puede decirse es que semejantes transformaciones tuvieron más 
envergadura y dificultad que las actuales que tanto desconciertan, por mucho que lo inmediato nuble la memoria.

Que la llamada Postmodernidad es hija malquerida (e incomprendida) de todo eso resulta obvio, pero a condición de recordar factores subyacentes como el ya viejo imperio de la compraventa universal y el darwinismo social que resurge en los últimos tiempos bajo la máscara de la austeridad, aunque a muchos intelectuales no parecen molestarles tanto como aquélla. El consabido cortejo de rasgos incluye la "vida líquida" (Bauman dixit) a lomos de un mundo hipertecnológico, o un difuso miedo y bastantes efectos pirotécnicos y mediáticos, todo ello no exento de unas cuantas ventajas materiales, hasta componer el agridulce invierno de nuestro descontento. Algunos coinciden con Nietzsche y hablan de nihilismo, otros prefieren destacar la liberación que implica y el precio normal que cualquier cambio se cobra, o simplemente se apunta al aumento de posibilidades en diferentes planos y usos, sin entrar en juicios de valor. Pero tal vez, con ser todo cierto en alguna medida, haya que fijarse en la peculiar contradicción entre la denominada "muerte de la tragedia" al modo clásico (que tanto lamenta R. Girard), entendida como ausencia de reflexión sobre los límites propios de un destino humano concebido dentro del cosmos, por un lado; y el continuo travestismo ideológico (ahora histórico, moderno) de nuestras penas y alegrías en aras del supuesto progreso, por otro lado, donde valor y precio se acercan peligrosamente y ya no parece haber criterios fiables de ninguna clase. Esta tensión perenne -pero ahora extrema e insuficientemente recordada- entre la condición humana estática y la dinámica abierta merece describirse como una crisis de identidad en toda regla, al margen de opiniones moralizantes...

Si llevamos estos rasgos al ámbito estético, se verá que el arte participa de ambas y que en consecuencia Nietzsche mezcla naturaleza e historia de modo paradójico para radicalizar el carácter creador y jovialmente destructivo de la libertad: el arte como algo autónomo en tanto que expresión privilegiada, arbitraria e insustituible de la voluntad de poder que es, dando cauce a sus ansias de trágico gozo. No cabe reconocer ahí armonía previa ni el apaño de salvar alguna inteligibilidad consoladora mediante la reconciliación, siquiera poética, de moralidad y felicidad, según soñaron Aristóteles o Kant (Pardo, 2007: 401, 423ss., 125s.). El arte vale por sí mismo, afirma el pensador intempestivo, extremando el gradual deslizamiento moderno desde la razón teórica a la razón práctica y de ésta hacia la razón estética (Kant como epítome), pero eso no basta para zanjar las desgarraduras y la permanente 
insatisfacción de una cultura que vive de cuestionarse y se devora a sí misma. Otro tanto ocurre con la dialéctica histórica (sea del espíritu, de la política o de la técnica), dada la imposibilidad de reconciliación simbólica y material que hemos aprendido definitivamente con los sangrientos episodios del siglo XX. Lo que queda es mejorar las condiciones de vida cuanto sea posible y optar entre verdades y sentidos que se escriben con minúsculas, pero plenos de dignidad. Y hacerlo con elegancia, sin afán de poder ni presunción, es lo que caracteriza al diletante que elige (elegans) con cierto conocimiento y estilo.

Por supuesto que lo hace en el marco de entramados causales objetivos y grados de verosimilitud subjetiva, pero ya no hay fines universales ni un sentido totalizador. Por eso cabe recordar sin avergonzarse el matrimonio entre ficción y verdad -la "invención verdadera" de la que habló Dante (Divina Comedia XVI, 124) y luego Vargas Llosa entre otros- no sólo en la literatura, pues en diversos campos de la existencia hay mentiras harto reveladoras y aun benéficas (Espinosa, 2010) que hacen valer cabalmente la etimología de fictio como acto de modelar y dar forma, es decir, como simulación más o menos lúcida mediante representaciones varias. Aquí hablamos del triunfo del simulacro que se reconoce a sí mismo: "Lo que distingue al pensamiento deconstructivo es sólo una actitud distinta en el ejercicio del juego de los simulacros (...) la producción de simulacros o metáforas, conscientes de ser tales" (Vattimo, 1986: 136). Se trata de recordar que los distintos juegos lingüístico-gnoseológicos (Wittgenstein) son pertinentes en su contexto, pero sólo dan fruto cuando asumen el rodeo y la dosis de ficción ínsita en todo quehacer del homo simbolicus, sumido en un complejo con diferentes valores de verdad. Y esto confiere penetración al arte, en el bien entendido de que -a diferencia de lo que admiraba Stendhal del Código Napoleónico- no requiere ejercer análisis ni "perpendicularidad al hecho".

Lejos de confundir realidad y ficción -volveremos sobre el tema de la verdad-, hay que aceptar hasta el final que todo discurso humano es un constructo que liga a duras penas lo que es inmanente a él y lo que aparece como trascendente, según diversos planos y marcos conceptuales, de manera que siempre conviene efectuar revisiones. La vida mezcla los niveles de la experiencia -con su carácter fronterizo entre el adentro y el afuera-, pero exige gran cintura, mucha curiosidad y una actitud abierta, trazos que convierten al diletante en amigo de lo inédito (el neoteropoioí del que habla Jámblico), sin someterse por ello a las modas. Digamos que admite la provisionalidad de casi todo sin claudicar ante lo evanescente, al igual que se interesa 
por la denostada cultura de masas sin arrugar la nariz, dado que su itinerancia humanista nada tiene que ver con el sibarita, el experto esotérico y mucho menos con el soberbio. El amateur no necesita imponerse, recuérdese, sólo amar.

Por otro lado, tiene que lidiar en el terreno estético con las pocas corrientes profundas y las múltiples de superficie que proliferan, en un contexto histórico marcado por el mestizaje, la dispersión y no pocas perplejidades desde el inicio del siglo XX: "En ninguna parte la separación de identidades y la fragmentación del tiempo y el espacio se escenificó de un modo más asombroso que en las artes, por ejemplo en los lienzos de Picasso y Braque, de Malévich, Kandisnsky, Carrà y Boccioni. La modernidad nació entre el hastío de la realidad y la verdad y las dudas sobre el propio lenguaje y las múltiples perspectivas de la experiencia" (Blom, 2010: 131). Algo similar podría decirse de la descomposición de los marcos de referencia en Kafka y Joyce o en el dodecafonismo musical, por dar ejemplos dispares, todo coetáneo además de la física relativista y mecanocuántica que tanto influyeron en la cultura. Han ocurrido muchas otras cosas después, claro está, pero con menos relieve y donde persiste el reconocimiento de la entraña multifacética e inabarcable de lo real. El problema está en que la confusión, las dudas y la ignorancia desdeñosa hacia las nuevas formas estéticas no han hecho sino crecer con el tiempo, al hilo tanto de los prejuicios como de las farsas pseudoartísticas, convertidas a menudo en una variante del mundo del espectáculo y dentro del establecimiento de los cánones (aquí como en todo) a cargo del mercado. Lo malo es que lo que se impone de hecho pretende hacerlo también de derecho, por eso el diletante juega sus cartas sin cinismo ante el desbarajuste y el descrédito generales, con el desafío de no someterse a chantaje alguno.

Para afrontar este magma, podría rescatarse una actitud filosófica entendida como capacidad de conectar diferentes cosas (ser nexólogo) a partir del arraigo primero en el mundo de la vida, de manera que "La racionalidad estética -la experiencia estética que se hace presente en nuestras estimaciones de gusto- no es una forma paralela de racionalidad; es más bien la urdimbre de todas ellas, a las que confirma o reprueba. El gozo estético es una experiencia que nos asegura consonancia o inadecuación con el mundo, por lo que tiene una función reflexiva que no está al alcance de un gran esfuerzo científico ni puede establecerse con una precipitada moralización (...) La estética no es un sustituto de la racionalidad, sino más bien su expansión y ensanchamiento, una atención que amplía sus horizontes y templa su 
receptividad" (Innerarity, 1995: 14s.). Se apela pues al cultivo de una sensibilidad inteligente, dúctil y porosa, que sirva como fuerza cotidiana y aglutinadora del saber, algo así como la aplicación a la vida de una brújula que no reposa en el conocimiento positivo ni en el juicio moral (aunque sea compatible con ellos, claro), sino en el ensamblaje intuitivo de nuestras diferentes disposiciones estéticas ante las cosas. No es que eso resuelva los problemas perennes, sino que la filosofía se convierte aquí en poética y narración de la existencia en el tiempo, lo que proporciona al diletante otra herramienta para dar cuenta de los avatares no formalizables, más allá o más acá de lo abstracto. Y también para propugnar una sociedad más democrática que respete la sensibilidad de los individuos, sin olvidar servirla con su pequeña aportación cívica. Nuestro aficionado, en fin, revuelve libremente en cuanto se le ofrece y, después de agradecerlo, elige y disfruta sin hipotecas... pero con intención de compartir.

\section{Un perfil para esta figura}

Hasta ahora hemos hablado del talante y del sentido histórico del diletantismo, pero llega el momento de concretar algunos de sus rasgos fundamentales -en el marco del singular artificialismo que lo caracteriza-, al hilo de ciertos autores y épocas.

3.1. Para empezar, Max Weber ha planteado bien las opciones a la vista de un mundo racionalizado y con una fuerte organización del trabajo: "En nuestro tiempo la obra realmente importante y definitiva es siempre obra de especialistas", de modo que la vocación del hombre de ciencia se alimenta de pasión e inspiración, pero sólo el trabajo arduo y con método -que es lo que le falta al aficionado- puede plasmarlas en sólidas obras (Weber, 1981: 191 y ss.). Hace falta usar "tapaojos" para centrarse en algo y mucho esfuerzo para dar cauce a la "ocurrencia" valiosa, aunque ésta siempre tiene algo de azarosa y sin imaginación creadora tampoco se puede brillar. Aparte de tener o no ciertos "dones", cosa que ignora de antemano, el científico debe "servir a la causa" del saber en lugar de "acumular vivencias" para autoafirmarse, bien es cierto que le cuesta limitarse a ser un mero experto y concede -como el artista y el aficionado-importancia decisiva de la inspiración y la entrega (Id., 195s.). He aquí, pues, la elección weberiana en favor del especialista y también lo que nos parece una renuncia y la pena secreta que la acompaña. 
Sin debatir ahora sobre el mundo alienado en que tiene lugar ese planteamiento, hay que referirse a otra cosa: "El trabajo científico, en efecto, está inmerso en la corriente del progreso, mientras que en el terreno del arte, por el contrario, no cabe hablar de progreso en este sentido (...) Una obra de arte que sea realmente 'acabada' no será nunca superada ni envejecerá jamás (...) Todo 'logro ' científico implica nuevas 'cuestiones' y ha de ser superado y ha de envejecer" (Id. 196s. y antes 195s.). Luego son dos formas diferentes de grandeza: el quehacer científico, siempre desmitificador, es inacabable y caduco por definición, pero sabe que nunca responderá a las preguntas por el sentido de la vida (Id., 199s.); y el arte tiene un estatuto atemporal que le permite cerrarse sobre la obra lograda, aunque carece de pruebas experimentales. De nuevo el peso de las escisiones...

Pues bien, el diletante elige la no especialización pero se mueve a caballo de ambos tipos (científico y artista) e intenta mediar en su aplicación a la vida, además de estar sometido igualmente a la pasión y la inspiración, por mucho que no lo sacrifique todo al trabajo. Pretende saber lo suficiente y practicar como aficionado, de manera que se beneficia de esas disciplinas sin descartar algún papel como buen divulgador ante la sociedad. Con lo que contribuye a la generación de la transdisciplinariedad y de lo que desde C. P. Snow se ha llamado Tercera cultura, algo nada baladí hoy día. Bajo este punto de vista, está liberado para reunir -mejor o peor- las dos funciones que separa Weber: "constatar hechos", que es la aportación del científico, y "preguntar por el valor" de cara al comportamiento, que lo es del artista (sin ser por ello "demagogo o profeta"), así como certificar en sí mismo el politeísmo axiológico y hacer visible el "sentido" de cada actividad dentro de su respectiva "visión del mundo" (Id. 212s. y 222s.). Como mediador, sintetiza un poco de lo que aportan el especialista y el esteta, sirviéndose del legado de los dos para prolongarlo. Su creatividad es derivada y de segunda mano, cierto, pero también exigente y fecunda ¿o es que está prohibida esta peculiar vocación mestiza, que además pretende reencantar el mundo por otra vía?

La historia de la cultura avala su presencia, aunque la figura del gran intelectual como crítico y traductor de cuestiones diversas haya quedado desvaída en los últimos tiempos. El diletante no es un sabelotodo ni un picaflor, tampoco un árbitro de la ideología o del gusto, pero reivindica aquella tarea para conectar ámbitos que no deben disyuntarse a tenor de la complejidad de la vida, lo que finalmente supone una nueva voluntad de inteligencia (Espinosa, 1993). Por otro lado, carece 
de cualquier pretensión de sistema y predica con el ejemplo, asumiendo límites a la vez que reivindicando su particular perspectivismo. Ni da lecciones ni deja que se las impongan, actúa en primer lugar por y para sí lejos del proselitismo, pero está siempre dispuesto a debatir sus criterios. Me parece, en fin, que en algunos aspectos el crítico de arte o el profesor de filosofía, pongamos por caso, encajarían bien ahí si son algo más que glosadores, lo que les obliga a un ejercicio de modesta originalidad. Algo similar, por cierto, afirma Habermas como propio de un pensamiento postmetafísico, cuando se refiere al papel mediador del filósofo entre el sistema de la ciencia y la acción comunicativa cotidiana, o al del crítico entre el arte y la vida (Habermas, 1990: 49). Se puede realizar la exégesis oportuna con la debida competencia y a la vez comprometerse, dado que la neutralidad es imposible y tal vez indeseable. Una labor aseada no debe confundirse con la asepsia.

3.2. El ejemplo histórico y temático que encarna Lichtenberg ofrece un excelente botón de muestra de un pensamiento aforístico libre de servidumbres en la forma y en el fondo: para el agudo escritor y reputado naturalista de la Ilustración no hay medidas universales para las cosas de la vida, so pena de homogeneizarlas en demasía, luego son los sujetos quienes evalúan cuanto se presenta ante ellos ( $A$ 110)², dentro de los marcos sociales y culturales que los alimentan, claro está. Este tono protagórico en absoluto es caprichoso, sino más bien la exigencia de asumir responsabilidades (sapere aude), dado que "el ser humano es siempre parcial y hace muy bien en serlo" (F-578), cuando no peca de hipócrita ni presume de sobrevolar incontaminado la realidad. Además de la fuerte impronta kantiana del autor, que le previene contra el realismo crudo, es preciso defender un proyecto de crítica personal: si la filosofía pura siempre "mantiene relaciones amorosas con la... impura" y el profesor de filosofía suele ser un traficante de opiniones ajenas (L-35 y K-246), parece muy conveniente apartarse de ese modelo academicista. Más vale ser un aficionado independiente al observar el mundo que un imitador encerrado en los libros de otros, sin desmerecer por ello su estudio.

La actitud de fondo combate las convenciones y la costumbre, tan necesarias en términos pragmáticos como adormecedoras cuando se convierten en rutina, puesto que la clave del despierto consiste en "poder ver, oír y sentir todo de nuevo" ( $\mathrm{H}$ 21). El empeño por prestar atención y renovarse cuanto sea posible se nos antoja el 
mejor antídoto contra el gregarismo y la repetición. No se trata tanto de volcarse en las grandes cosas, a menudo con pose retórica, como de atender a "los pequeños sucesos cotidianos" donde se ventilan las auténticas cuestiones morales (B-195), pues el interés genuino por las cosas menudas conduce al logro de las otras. De manera análoga, Lichtenberg afirma que de nada sirve ser muy espiritual y/o cerebral si uno no sabe coser un botón (D-452) y añade que, aunque un corazón puro es cosa excelente, también lo es una camisa limpia (F-885). La ironía purga el engreimiento y pone los pies en la tierra para desenvolverse en el día a día, dado que el buen gusto también consiste en resolver lo prosaico sin perder la compostura. El diletantismo que rescatamos, en fin, es el de quien hace de la jovialidad y la ligereza el mejor enfoque para la vida, según dice el autor alemán que le enseña la propia experiencia ((B-81), claro precedente del espíritu travieso que luego reivindicará Nietzsche en pasajes memorables. La alegría proporciona el tono adecuado para entender y convivir, mensajera de la sabiduría hallada en lo ordinario. Quizá el resumen definitivo sea este: "Hacer que cada momento de nuestra vida sea el mejor posible, independientemente de qué mano del destino provenga y de si es favorable o desfavorable: en esto consiste el arte de vivir y el verdadero privilegio de un ser racional" (G-212). Con lo que retornamos al ámbito de las actitudes volcadas en la praxis, a la misma distancia del optimismo iluso que del pesimismo recalcitrante. Esta suerte de posibilismo ambicioso al servicio del gozo no sabe de compartimentos estancos en el saber, sino que se atiene a la divisa ilustrada de conjuntarlo todo en el seno de una racionalidad ampliada y tan dichosa como pueda serlo. Nuestro amateur se aplica sin dramatismo y hace de su amor un motivo de alegría, a pesar de los muchos pesares.

3.3. Hemos planteado la cuestión de las vocaciones y definido algunos rasgos del prototipo que nos guía, ahora conviene reparar en la génesis histórica del gusto que lo vertebra. Y nadie mejor que P. Bordieu, como es sabido, para tratarlo: no sólo por la célebre atribución de la distinción cultural a condicionantes sociales de clase y estatus, ni por acuñar el útil concepto de capital simbólico, junto a y en pugna con el económico y el humano, sino especialmente por denunciar la violencia simbólica que hace pasar por natural lo que no es sino obra histórica orientada a la dominación. Sobre esta base, el diletante sería quien intenta rebasar esas 
determinaciones sociológicas (aunque tenga sus pre-juicios y ataduras), entre otras cosas porque no reconoce dictados ni acata, por ejemplo, la definición burguesa de arte instituida en algo universal y canónico. He aquí otra forma de reconocer el artificialismo genealógico del que hablamos.

El eje es la noción de habitus, que recoge el rico legado teórico-práctico sobre la vida que el tiempo genera y transmite, de modo que los individuos lo hacen suyo cual "historia incorporada" o interiorizada, por un lado, e "historia objetivada" en toda clase de productos culturales, por otro, lo que a su vez da lugar a diferentes campos de realidad que interactúan entre sí (Bordieu, 1982: 41s.). Ahí se incluyen multitud de presupuestos, ideas, fines y herramientas, hasta configurar toda una concepción del mundo con sus códigos omnipresentes. La novedad frente al discurso de Dilthey es que esa estructura es definida como palanca del poder y llega a convertirse en algo más que una segunda naturaleza o paradigma del sentido común, para alcanzar el rango de verdadero "inconsciente" colectivo cuya gran eficacia estriba en que resulta invisible: lo supuestamente universal -pero sólo consuetudinario- se transforma en hexis individual y en doxa del grupo, sin siquiera saberlo (Bordieu, 1997: 23). Y esta ignorancia de base impide cualquier cuestionamiento del statu quo de la manera más eficaz, lo que obliga a realizar una arqueología que lo desenmascare similar a la de Foucault. Pues bien, el diletante lucha por tener una mayor consciencia de todo ello y construir su disposición personal gracias al hábito de un juicio flexible y ecléctico, para moverse con brío entre aquellos diversos campos de realidad. Y no lo hace por prurito individualista, sino para escapar a esa violencia simbólica que le ciega y enajena en caso contrario.

En cuanto al arte, esta génesis de la subjetividad a través del habitus prevalece y tiene el mismo carácter contingente, como respecto al pensamiento en general. El resultado del análisis es que no hay arte en abstracto ni un canon transhistórico, ya que éste sólo surge de la continuada elevación a regla de las circunstancias y casos concretos (Bordieu, 1992: 420). Hay tradiciones y criterios consensuados, así como valoraciones motivadas, pero justamente se trata de no hipostasiarlos ni hacer de ellos un tótem inobjetable. Si uno piensa, por poner un sencillo caso, que la ópera era un mero divertimento para la aristocracia del XVIII (que charlaba sin descanso durante las representaciones) y que ahora parece poco menos que una muestra de arte sagrado, lo entenderá mejor. Lo mismo puede decirse de los vaivenes históricos de otras formas estéticas, siempre ligadas - no se olvide- a la 
infraestructura material, técnica, laboral y sociológica que las condiciona, como ha probado D. Sassoon con todo lujo de detalles (Sassoon, 2005). Nuestro aficionado culto, el que admira el mundo en su multitud de facetas, sabe que es hijo del tiempo a todos los efectos y toma buena nota de ello, a la par que guarda como un tesoro duradero las decantaciones propias de una sensibilidad alerta. Aquí, como tantas veces, el ser y el devenir tienen que hacerse conscientemente compatibles, al igual que la unidad y la diferencia: ése es su proyecto de vida.

Por último, quisiera subrayar el carácter afirmativo que se desprende de todo lo anterior: el diletante tiene una vocación polígama, no es amigo de una razón ajena a la felicidad y sabe que casi toda su experiencia vital ha sido filtrada por aprendizajes que provienen de la historia. Quiere encajar en el mundo y descarta una actitud de absoluta sospecha o desconfianza, como algunos entienden la crítica y rebeldía, ya que busca el acuerdo matizado con lo real, por muy arisco que esto sea: "La filosofía y el arte son igualmente cultivos de la atención hacia la realidad, y no ejercicios de distracción. La filosofía puede ser considerada como una de las bellas artes en la medida en que coopera con ellas en la ampliación y concentración de nuestro sentido de realidad. Son verdaderas estrategias de resistencia contra la desrealización" (Innerarity, 1995: 44). Vivir exige atender, esto es, focalizar e integrar, precisamente lo contrario de la fuga o el rechazo, de ahí que éste sea el vínculo entre las diferentes dimensiones mencionadas. No es fácil ni siempre agradable, pero parece lo único que llena la vida de sabor y la engarza con eso que llamamos realidad.

\section{Dos modelos de entender el arte en liza}

De modo esquemático, puede decirse que hay dos grandes posiciones a la hora de reconocer el fenómeno artístico: la primera afirma su ímpetu trascendente, cuyo contenido es externo a la mera subjetividad y comunicable en lo esencial, a pesar de que haya grados y múltiples condicionantes históricos; la segunda enfatiza su carácter particular y convencional, construido y contingente, donde las interpretaciones posibles se disparan. Allí hay cierta verdad que se impone por sí misma, aunque ayudada por el conocimiento del contexto, aquí hay mayor discrecionalidad electiva y se requiere el papel del crítico que hace hablar a la obra. Obviamente, también 
hay elementos en común y caben muchos detalles, pero importa diferenciar entre la actitud que afirma una metafísica del arte y la que lo niega.

4.1. George Steiner es un preclaro representante de la primera opción y ofrece un notable catálogo de argumentos al respecto: para superar "la crisis del significado del significado" acontecida a caballo de los siglos XIX y XX, es decir, la "ruptura de la alianza entre la palabra y el mundo" (Mallarmé) así como la fragmentación del sujeto (Rimbaud) que desembocan tanto en la disolución del mundo como de la conciencia (Steiner, 1991: 118-125), hay que recurrir a la hipótesis de la trascendencia creadora de Dios como garante del significado estético, ya que "supone el paso, más allá de lo ficticio o lo puramente pragmático, desde el significado a la significatividad" (Id., 14). Sólo ese apoyo permitiría establecer una semántica universal, una suerte de logos que asegure la "presencia" (Id., 151) de algo real y compartido, allende los procesos deconstructivos (Derrida) y el examen inacabable de las relaciones internas a la obra con sus distintos lenguajes. Dicho de otra forma, para salvaguardar el ser y el valor del arte (aunque éste no sea verificable ni refutable, sino siempre un hecho singular, Id. 97s), se requiere dar el salto hacia una estructura ontológica y de sentido que asegure la conexión cierta entre objeto y sujeto en general, en cuyo seno habite la comunicación.

En esa medida, el arte "serio" produce una vivencia transformadora cuando es bien asimilado por el intelecto y la sensibilidad, llena de carga ética y política además de contar con los "significados vivos de lo estético" comunes al creador y el receptor atento, más aún si éste tiene informaciones que le ayuden a comprender ese contenido (Id., 176s. y 181). Hace falta un considerable aprendizaje donde no hay certezas, sólo hitos provisionales y "tanteos" frecuentes, dado que la captación es siempre frágil. Pero a la postre se confía en la efectiva comunión entre sujetos y de éstos con el mundo, tal como expresan la centralidad antropológica del lenguaje natural o la energía primaria y arrebatadora de la música concebida como la forma artística absoluta. Por razones evolutivas y psicosomáticas a las que se suma la educación, el humano se abre a lo otro de sí, con el arte convertido en vehículo privilegiado para mostrar esa "presencia de radiante opacidad" y el misterio que somos (Id., 256 Y 239). Luego estamos ante un proceso estético más bien indirecto e incompleto, cuando no enigmático, pero a la vez imprescindible para conocernos y saber dónde habitamos. 
En relación al trasfondo teológico, hay que subrayar que el artista (como dicen de sí mismos Gauguin, Picasso o Matisse) crea para situarse frente a una creación anterior, esto es, contrapone su obra cual demiurgo humano a la de Dios, sea para completarla o rebatirla, pero siempre desde el supuesto de que hay una realidad incontestable a la que sumarse, aunque Dios fuera una hipótesis. Al final -concluye Steiner- debe aceptarse la existencia de un "continuum entre temporalidad y eternidad, entre materia y espíritu, entre el hombre y 'el otro'", con el propósito de vencer nuestros límites en lo posible y luchar con fuerza renovada contra la muerte y el sufrimiento, sea por vía teológica o laica (Id., 275 y 280, antes 257). Lo contrario es negar la evidencia transformadora de las experiencias estéticas profundas, resignándose ante la palabrería estéril de un discurso autorreferente que escamotea la entidad de la obra y la conexión entre los diferentes agentes aludidos por ella.

Steiner sabe que no hay demostración posible de su tesis, pero afirma que sólo de esta manera puede mostrarse la densidad y potencia del arte, que es tanto como decir de la vida humana misma y de la realidad en su conjunto. Por otro lado, buena parte de la historia del arte occidental ha girado en torno a la pretensión de hacer visible lo invisible (sea lo sobrenatural, los sueños, los deseos, etc.), o apuntar al reverso emancipador de una realidad alienada, según reclamaba Adorno. Acaso todo pueda resumirse en que lo inteligible se abre paso hacia lo sensible a través de la imitación de los eidoi divinos o humanos (Panofsky, 2013), sin olvidar otras instancias a-lógicas tales como los impulsos impersonales rescatados por las vanguardias con medios expresivos diferentes. El caso es que el arte sería, bajo esta lectura, una paradójica afirmación de lo oculto que se manifiesta (irevela?) mediante formas que sólo a través de él pueden concebirse, e incluso su invocación por vía negativa, a la manera de los místicos. A nadie puede extrañar entonces su carácter escurridizo e inclasificable, esa capacidad ambivalente que abarca lo visible y lo opaco, lo actual y lo potencial, lo que se percibe y lo que se intuye. Por eso es tan valiosa como vulnerable (nunca segura ni manufacturada del todo) la experiencia estética y la comunicación que abre.

De cualquier forma, no cabe renunciar a la verdad singular que encierra (siquiera como utopía, en palabras de F. Calvo Serraller) y mucho menos al contacto con lo real que permite, según ha proclamado el veterano poeta y escritor Y. Bonnefoy: "La poesía está para recordarnos que todas las palabras, incluidas las que usamos automáticamente, o tanto que parecen gastadas y poco relevantes, son las responsables de la realidad 
(...) Fundamentalmente la poesía debe decir: 'Existe una Realidad', debemos ser parte del mundo, no debemos dejarnos llevar por esa distracción que nos hace aceptar nuestras existencias como algo abstracto, o resignado a la irrealidad. iLa poesía es aquello que exige la existencia del mundo!" (ambas referencias en El País Babelia, 8-2-2014, p.11). Se trata de recuperar la relación nuclear entre palabra y mundo, aun problemática, como baluarte ya mentado contra el vaciamiento de la vida y la pérdida de lazos. Algo que vendría a refrendar la hipótesis antropológica de que la cultura es la manera simbólica de vencer el íntimo desarraigo que el humano siente, a diferencia del animal, para unirse a la naturaleza de la que fue exiliado en tanto que pensante. Así, la estética es uno de los puentes tendidos para lograrlo como anclaje entre lo que, no sin ironía metafreudiana, podría llamarse el principio de realidad vinculado en este caso al principio de placer. Quizá por regalar esta incierta síntesis es el arte tan conmovedor y salvaje..., en el sentido de imprevisible y poderosa revelación de lo que sentimos y necesitamos.

4.2. La segunda gran lectura pone el acento en el artificialismo (por contraste con el anterior modelo metafísico o natural), uno de cuyos más agudos representantes es Oscar Wilde, paradigma de autor con "encanto" -en palabras de Borges-, aunque no siempre lúdico ni superficial. Lo que ahora importa es la concepción referida en el largo ensayo titulado El crítico artista (1891), y después habrá que ver cuál es la posición del diletante respecto a estas dos visiones y sus argumentos.

Wilde parte del axioma de que las dos artes supremas son la Vida y la Literatura ${ }^{3}$, es decir, la vida y su perfecta expresión; pero con la peculiaridad de que, frente al "fracaso" de la primera por ser un tobogán de placeres, amarguras y desengaños que además nunca pueden reproducirse iguales, el arte es capaz de fijar para siempre los estados de ánimo, lo que permite anticiparlos y deleitarse con ellos a voluntad (Wilde, 1986: 26 y 59). Se trataría de anotar como haber el conocido contrapeso estético ante la experiencia fugitiva y la libertad de elección que aporta a la hora de revivir ciertas emociones. Con lo que se bascula ahora hacia lo subjetivo, alimentado el sujeto por los contenidos artísticos que suscitan afectos límpidos, mientras que en el día a día son mucho más sucios e inmanejables. La vida está limitada por la circunstancia, se expresa incoherentemente y sin "la delicada correlación entre la forma y el espíritu", pero cabe superarlo todo: "Por medio del arte y sólo por él 
podemos lograr nuestra perfección; el arte y solamente el arte nos preserva de los peligros sórdidos de la existencia real" (Id., 64 y s.). A la clásica función catártica se suma el aquilatamiento estético, el único que puede hacernos mejores dosificando nuestras pobres fuerzas físicas y mentales hasta conducirlas a una suerte de elevación bien temperada. El arte informa y pule, saca brillo a la vida.

Esto supone cierto tipo de "inmoralidad" que consiste en alejarse de la pragmática social y retirarse al ámbito de la inútil contemplación, "Porque la emoción por la emoción es la finalidad del arte y la emoción por la acción es la finalidad de la vida"; lo que a su vez implica que las intenciones convencionales son bienintencionadas pero insoportables y vulgares frente a la esterilidad grandiosa de las "bellas emociones" y el dificilísimo arte de no hacer nada (Id., 66). Junto a la crítica irónica hacia la cosmovisión burguesa y en particular victoriana -con sus muchos logros económicos y científico-técnicos que la ensoberbecen-, Wilde reivindica el papel cualificador de lo intangible e improductivo. El arte no cambia el mundo, su carácter gratuito escapa a toda consideración heterónoma y se distancia escéptico del proyecto edificante propio de las vaguedades metafísicas o religiosas. Lo suyo es la sensualidad de lo concreto, espiritualizada la materia gracias al tono "impráctico" en la recreación de los "estados del alma" que los filisteos nunca entenderán (Id., 67s y 71). No hay nada que justificar ni que sustituir, por lo que tampoco se huye de la vida -como pudiera creerse-, sino que se vive gracias a la intensidad destilada que el arte procura.

La pose del dandi no debe llevarnos a confusión sobre las intenciones éticas del irlandés: los sentidos y el intelecto se aúnan en el gozo de lo particular para huir de toda bajeza, como en los griegos y en Goethe, nos dice. Integrar las capacidades del sujeto y llevarle al contacto prístino con el ente bien delimitado ("la pura impresión sintética" de lo perceptivo y lo intelectual que corresponde al "sentido estético", Id., 52) rinde un gran servicio, de manera que el acceso a la trascendencia del objeto tiene un sesgo nominalista, si vale la expresión. Y tal es la vía paradójica en que se presenta la Belleza, que "posee tantos significados como estados de ánimo tiene el hombre. La Belleza es el símbolo de los símbolos. La Belleza lo revela todo porque no expresa nada. Cuando aparece ante nosotros, nos muestra con ardientes colores todo el Universo" (Id., 49). El símbolo connotativo de lo bello rebasa al signo denotativo singular y amplía el horizonte hacia la armonía del conjunto. Se transita desde la vivencia única hacia la plenitud afirmativa de lo existente, pero de nuevo libre de ganga: la belleza decanta el mineral puro del ser, es el plus de sentido que trasciende y sublima lo concreto. 
Así las cosas, la función del "crítico artista" resulta imprescindible porque desentraña el significado estético y filtra lo que de divino hay en un mundo imperfecto. La crítica "elevada" es como una "creación dentro de otra creación" (la de los artistas), pues ya usa materiales escogidos y autónomos, de ahí que sea incluso una forma superior u obra de arte de segundo grado, pues no depende de modelos externos ni de la miserable verosimilitud con que se paga a "los fastidiosos ensayos de la vida doméstica o cobarde" (Id., 45). Esta liberación de ataduras convierte a la crítica en el "relato del alma" de quien la realiza, más excelsa que la Historia de lo general y más real que la abstracta Filosofía, lo que la define como la "única forma civilizada de autobiografía", ajena a los acontecimientos y sólo volcada en "las pasiones imaginativas y los estados superiores de la inteligencia"; por tanto, la crítica es "esencialmente subjetiva e intenta revelar su propio secreto y no el secreto ajeno. Porque la crítica superior se ocupa del arte no como expresión, sino como emoción pura" (Id., 45 y s.). He aquí el giro definitivo hacia la subjetividad que enfrenta por completo esta posición con la más objetivista de Steiner (1991: 22s. y 29s., 55), quien carga precisamente contra la crítica y la hermenéutica que desvirtúan el contenido artístico desde fuera, cuando éste debe hacerse valer por sí mismo (aun facilitado por una buena preparación). Wilde, en cambio, habla desde la autorreferencialidad del crítico que recrea la obra dada, ceñido a sus vivencias y estados de comprensión más sutiles.

En la impresión subjetiva que se antepone a la expresión objetiva, el crítico es más que un mero intérprete de la obra del artista (quien antes lo fue del mundo) y cumple la función de "adensar su misterio", para lo cual requiere conocimiento sobre el tema y sus circunstancias, tanto más si es un intérprete en el sentido específico de ejecutar una pieza musical o representar una obra de teatro. De hecho, sólo a través de la propia personalidad cabe aportar algo, pues a ella se revela el arte generado por otras personalidades, y así puede "extraer sus impresiones casi únicamente de lo que haya tocado el Arte. Porque la vida es terriblemente defectuosa desde el punto de vista de la forma; sus catástrofes hieren injustamente y sin motivos" (Id., 58, y antes 56s.). Esta idea se repite y bien puede interpretarse como la transformación de la crueldad de lo real (por su carácter "crudo", según la etimología) y la captura de la pura forma que sirve a la perfección de la persona, en vez de dañarla. Wilde no es un cobarde ni un snob y afirma que la "vida contemplativa" propia del "hombre culto" es aquella que "por medio de una delicada erudición y una laboriosa eliminación 
ha hecho el instinto consciente e inteligente, y puede separar la obra que posee distinción de la que no la tiene, y así, por contacto y comparación, adueñarse de los secretos de estilo y escuela, escuchar sus voces, comprender sus significados y desarrollar ese espíritu de curiosidad desinteresada que es la verdadera raíz y la verdadera flor de la vida mental (...) la lucidez intelectual" (Id., 70). Luego el subjetivismo debe ser afinado, nada arbitrario o sentimental, pues los estados del alma superiores se fraguan sobre una espontaneidad bien educada para discernir y se ganan a pulso mediante el estudio y el afán gratuito por conocer...

4.3. Ambos modelos estéticos asumen la existencia de unos significados accesibles y compartidos (que otros negarán) y coinciden así con el diletantismo que nos ocupa, opuestos a la disolución de cualquier marco semántico de referencia, aunque los matices difieren: Wilde enfatiza la mediación del intérprete y la depuración formal de la existencia ordinaria, mientras que Steiner prima el contacto directo con el mundo a través del polo objetivo del arte que incluye las desgarraduras informes del ser. Curiosamente, el primero resulta un platónico sin teología, mientras que el segundo ve la creación artística -nacida de la pobre finitud- bajo el paraguas de la creación divina. En todo caso, aquella trascendencia común del significado salva la función cognoscitiva y expresiva del arte, que a su vez aúna sensibilidad, pensamiento e intuición.

El amateur está a medio camino de esos dos arquetipos y toma elementos de cada uno: en primera instancia, hay una cercanía -por el estilo personal- entre el crítico definido por Wilde y nuestra propuesta, si bien el aficionado tiene menos aspiraciones y no se aparta de la vida para consagrarse a la belleza sublimada; su proyecto no es elitista y está imbuido del carácter mestizo de toda existencia, aun a costa de renunciar a la perfección. Sin embargo, ambos convierten la subjetividad irreductible en piedra de toque para la fruición, desde un juicio que nunca aspira a ser imparcial. Digamos con Wilde que coinciden en educar su temperamento para hacerlo más y mejor apasionado; que no ceden a la costumbre y la rutina establecidas, pero tampoco son esclavos "de sus propias opiniones"; y que entienden el arte como algo distinto de la moral para combatir ante todo el "pecado" de la vulgaridad y la estupidez (Id., 80-84, 98). Crítico y diletante no acatan referencias cerradas de ninguna índole, aunque el segundo se quiere más modesto, sin considerarse un faro para nadie, 
inmerso como está en lo que tiene entre manos en cada momento. El aficionado vive toda experiencia, no pontifica en torno a la belleza pero defiende la solidez de sus gustos, lo que nunca hará es imponerlos ni regañar a nadie por los suyos.

De otra parte, esta limitación que no acepta instancias metafísicas ni religiosas como algo inherente al fenómeno artístico, aleja al diletante de lo que defiende Steiner: una cosa es afirmar el contacto con lo real y otra asumir un supuesto armazón en lo dado, una cosa es suscribir los contingentes significados intersubjetivos de las obras de arte y otra aceptar que haya una verdad objetiva que se impone por sí misma. Los fenómenos artísticos sólo hablan en la intimidad, a condición de que cada uno ponga su intransferible sensibilidad a la escucha con los mínimos presupuestos posibles. Sin embargo, hay en ambas posturas una fuerte conexión entre sujeto y mundo (ahora sin la mediación de intérpretes privilegiados) que incluye cualesquiera adherencias vitales junto a lo propiamente estético. El amateur tampoco es un contemplativo exquisito al modo de Wilde, sino un activo pescador de perlas eventualmente imperfectas y valiosas por sí mismas, sin recurrir a la armonía universal en la belleza. Claro que eso también le hace renuente a ver misterios insondables en las vivencias artísticas, con frecuencia más sencillas y efímeras de lo que Steiner trasluce. En una palabra, para el diletante hay realidad compartida, sí, pero sin garantía alguna de que exprese "lo eterno" ni responda al trasfondo inagotable de lo invisible que sale a la luz por diferentes vías y épocas. A este respecto, salvando las distancias, es más bien un agnóstico que a veces se ilumina e incluso siente fervor, sin cejar nunca de buscar.

\section{A modo de conclusión}

La figura puede caracterizarse - por vía epistémica- como un nominalista a la par que realista moderado, en la medida en que se atiene al dictamen subjetivo ante lo particular pero es consciente de que vive en marcos intersubjetivos culturalmente mediados. Nada tiene que hacer aquí el puro relativismo ni el todo vale, tampoco el sinsentido permanente y la fragmentación extrema de la experiencia; lo que importa es el reconocimiento de una plasticidad ética y estética que se alimenta de muchos ingredientes en aras de una síntesis personal variable. Como se dijo al principio, el diletante es ecléctico y nómada, respetuoso con los criterios de valor 
que le parecen convincentes durante el tiempo que sea, siempre provisionales y sometidos a su última palabra. Ejerce casi el método del ensayo y error, aunque no haya experimentum crucis que pueda generalizarse ni emoción o símbolo que valga para todos. Lo suyo es más cotidiano y falible, pero también complejo: cabalga como mejor puede en el filo de la materia y la forma, de la carne y el espíritu, y lo hace sin red ontológico-conceptual de seguridad. Es su apuesta...

Tampoco hay dramático dilema entre verdad y ficción ya que se complementan: "Reconocer que existe una dimensión cognoscitiva en el arte y una dimensión artística en la filosofía se presenta como la única manera de superar la estéril contraposición entre el discurso de la verdad objetiva y el de la ficción fantasiosa. El arte y la filosofía conspiran juntos en la tarea de ampliar la experiencia humana y fortalecer su atención. Están igualmente tan interesados en la vigilia del hombre, que no quisieran pagar con el precio de despojar a la realidad de riqueza y significación (...) No se trata tanto de descubrir lo estético en la experiencia cotidiana, como de salvar la experiencia cotidiana en lo estético" (Innerarity, 1995: 57 y s.). Se podría incluir ahí la dimensión estética de la ciencia, como tantos matemáticos y científicos han señalado siempre, ya que también participa del empeño común por despertar a los seres humanos. Lo decisivo es la apelación a vivir el día a día traspasado por ese toque poético, mayor o menor según las circunstancias, pero real y libre. Como dijo García Márquez al recibir el Nobel, la clave es "La poesía, en fin, esa energía secreta de la vida cotidiana que cuece los garbanzos en la cocina y contagia el amor y repite las imágenes en los espejos" (fácil de hallar en la red). Pues bien, el diletante atiende ese requerimiento en lo ordinario, procurando alejarse de las actitudes pretenciosas y prejuiciadas.

Uno de los pensadores que mejor encarnan este modelo es Montaigne -quien se entiende a sí mismo como amateur- y con él resumimos nuestro camino: primero, defiende la bondad moral e intelectual frente a la pedantería libresca y la erudición no asimilada (Montaigne, 1985: I, XXIV, 94), desde la frecuentación del mundo y sus enseñanzas: "Tantos humores, sectas, juicios, opiniones, leyes y costumbres, nos enseñan a juzgar cuerdamente los nuestros", con perspectiva y sano relativismo (Id., I, XXV, 112). El buen aficionado se curte en el trato con los seres y las cosas, sin aspirar a la maestría teórica ni a otra cosa que su perspectiva móvil y tolerante. En segundo lugar, el aprendizaje que proporcionan los buenos instructores y la experiencia aspira a unir el juicio práctico y los diversos saberes, de manera que este bloque integrado 
se aplica a mejorar nuestro "temple" y en ello consiste la virtud (Id., I, XXIV, 96s.). El diletante es el tipo que interpreta y practica, según la polisemia de estos vocablos, en pos de su eventual virtuosismo. En tercer lugar, la virtud está unida para Montaigne a la voluptuosidad y el placer (al modo epicúreo o espinozista), entendida como la afirmación de la potencia interna que a su vez genera desprecio hacia la muerte y el dolor en beneficio de la tranquilidad de ánimo (Id., I, XIX, 48s. y I, XXV, 116). Y es que si el amateur no demostrara con su ejemplo que es mucho más fecunda la dicha que la tristeza, tendría que cambiar sin duda su conducta, intereses y aficiones.

Como otros autores citados, Montaigne encomia los aprendizajes incorporados al vivir, dado que "El verdadero espejo de nuestros discursos es la marcha de nuestra vida" (Id., I, XXV, 122), lo que debería traducirse al cabo en una actitud afirmativa y jovial. Ni que decir tiene que esto choca con el rostro "adusto, torvo y horrible" que a menudo tiene la filosofía, considerada inaccesible o inútil por muchos, cuando en realidad "sólo nos predica alborozos y bonanzas, y no le va bien una traza triste y melancólica (...) El alma en que se aloja la filosofía debe, con su propia salud, infundir salud al cuerpo, haciéndole mostrar, incluso en lo exterior, reposo y sosiego, dándole una seriedad amable, un talante activo y alegre y un rostro contento y bondadoso. La más expresa señal de sabiduría es un gozo continuo" (Id., I, XXV, 115). No se puede condensar mejor lo que aquí nos atañe (confirmado después literalmente por Spinoza) y que no es sino el cultivo de nuestro gusto por disfrutar con relajado empeño, lo único que sin apenas darnos cuenta nos acerca a la virtud y la sabiduría. El diletante no presume ni se queja, sino que es fiel a sí mismo a través de sus dedicaciones y ofrece a quien la quiera esa ligereza filosófica, que no frivolidad, con que ensaya la vida.

Se trata, por último, de un proyecto humanista basado en la adecuación prudente a los límites, ajeno por tanto a la grandilocuencia, pues no se olvida de conjugar lo deseable y lo posible: "Es perfección absoluta, y semejante a la divina, saber gozar lealmente del propio ser. Buscamos otras condiciones porque no entendemos las nuestras, y nos salimos de nosotros mismos por ignorar lo que nos compete hacer. Aunque andemos con zancos, siempre andaremos con nuestras piernas, y en el más elevado trono del mundo siempre sobre nuestro culo nos sentamos. A mi entender, las más hermosas vidas son las que se ajustan al modelo humano y común, con buen orden y sin milagros ni extravagancias" (Id., III, XIII, 276s.). Hecho este soberano recordatorio, que habla por sí mismo, parece indicado ver la excelencia como una 
síntesis personal de ética y estética que combate la dureza de la vida sin rencor y se echa en brazos del gozo. Y es que, desde otro ángulo, el gran arte de vivir estribaría en conciliar hasta donde sea posible el aspecto prosaico y el poético, el sapiente y el demente, el utilitario y el lúdico, que tienen todas las biografías a través de múltiples combinaciones (Espinosa, 2013), lo que deja a nuestro aficionado al final de las palabras y le conduce de una vez a ponerlas en práctica.

\section{Bibliografía}

Blom, Ph.: Años de vértigo. Cultura y cambio en Occidente 1900-1914, Barcelona, Crítica, 2010. Bordieu, P.: Lección sobre la lección, Barcelona, Anagrama, 1982.

- Meditaciones pascalianas, Barcelona, Anagrama, 1997.

- Las reglas del arte, Barcelona, Anagrama, 1995.

Erasmo de Rotterdam: Elogio de la locura, Madrid, Sarpe, 1984.

Espinosa Rubio, L.: "Los sofistas y el artificio del saber", Estudios Filosóficos 126 (1995) 339-357

"Por una nueva voluntad de inteligencia", en VV.AA: Problemas fundamentales del conocimiento, Sociedad Castellano-Leonesa de Filosofía, Salamanca, 1993, pp. 131-140.

"Vida y narración: entre la filosofía y la literatura", Isegoría 42 (2010) 105-128

"La expresión bidimensional de la vida humana. Notas para una antropología de las polaridades", en J. Ma Torralba (ed), Mundos de papel. Las difusas fronteras entre ficción y filosofía, Madrid, Biblioteca Nueva, pp. 245-261

Habermas, J.: Pensamiento postmetafísico, Madrid, Taurus, 1990.

Hegel, G. F. W.: Ciencia de la Lógica, 2 vol., trad. Augusta y Rodolfo Mondolfo, Buenos Aires, Ediciones Solar, 1968.

Innerarity, D.: La filosofía como una de las bellas artes, Barcelona, Ariel, 1995.

Lichtenberg, G. H.: Aforismos (Antología), trad. J. del Solar, Madrid, Edhasa, 1991.

Luciano de Samósata: Diálogos de los dioses, de los muertos, de las cortesanas, Madrid, Alianza, 1987. Montaigne, M.: Ensayos, Barcelona, Orbis, 1985.

Panofsky, E.: Idea. Contribución a la historia de la teoría del arte, Madrid, Cátedra, 2013.

Pardo, J. L.: Esto no es música. Introducción al malestar en la cultura de masas, Barcelona, GalaxiaGutenberg y Círculo de Lectores, 2007.

Sassoon, D.: Cultura. El patrimonio común de los europeos, Barcelona, Crítica, 2006.

Steiner, G.: Presencias reales, Barcelona, Destino, 1991.

Stromberg, R. N.: Historia intelectual europea desde 1789, Madrid, Debate, 1990.

Trías, E.: La aventura filosófica, Madrid, Mondadori, 1988. 
Vattimo, G.: Las aventuras de la diferencia, Barcelona, Península, 1986.

Weber, M.: El político y el científico, Madrid, Alianza, 1981.

Wilde, O.: Ensayos. Artículos, Barcelona, Hyspamérica-Orbis, 1986.

\section{Notas}

¿ 1. Por motivos retóricos y de sentido prefiero "tristeza" a pena o luto, y "cosas finitas" en lugar de "finitud".

2. Las letras responden al cuaderno (por años) de las anotaciones y el $n^{0}$ al aforismo en cuestión, según la edición canónica de los Sudelbücher (Munich, 1968-71) y la traducción citada en la bibliografía.

3. Las mayúsculas son del autor irlandés. La literatura es superior a la pintura, escultura y arquitectura porque expone la vida en movimiento, sujeta al tiempo y sus mutaciones: aporta el "ciclo completo del pensamiento" y sólo la música la supera como misterio nunca agotado y siempre abierto (Wilde, 1986: 42s. y 50s., respectivamente). 